\title{
An exploration of pre-service teachers' attributions in English
}

\author{
Cevdet Yilmaz ${ }^{1 \mathrm{a}}$ \\ ${ }^{1}$ Faculty of Education, Çanakkale Onsekiz Mart University, 17 100, Çanakkale, Turkey
}

\begin{abstract}
With the developments in cognitive psychology, language learners' beliefs have received considerable attention in the domain of language teaching and learning. One area that merits investigation as to what the learner brings to this educational process is learner attributions which are commonly defined as 'perceived causes of success and failure'. This paper investigated pre-service teachers' perceptions of student attributions and their performance in English. Attributions are categorized as either internal (for instance ability) or external (for instance task difficulty). Motivated by these theoretical concerns, the study investigated the attributions of 122 pre-service teachers majoring in English and the connections between attribution and proficiency and gender. The study concludes with a set of far-reaching pedagogical implications and suggestions for learner training and teacher action in the EFL classroom. The results underscore the need for pre-service students to become aware of their own perceptions with regard to students' success and failure in English.
\end{abstract}

Keywords: attribution; success; failure; teacher education

\section{Introduction}

Recently there has been a considerable amount of interest in a variety of different areas that draw upon the field of psychology in teaching a foreign language. Given the origins of the attribution theory, related literature has revealed that the concept of attribution has its roots within the discipline of educational psychology [1, 11, 12, 13 and 14]. Driscoll [4] suggests that attribution theory can be linked to theories of motivation, which at one time, were only considered in behavioral views of psychology and learning. However, as he noted, in the 1960's and 1970's a shift began to occur that leaned more towards cognitive views of learning and researchers sought to understand what motivates a person to do something. This shift resulted in the emergence of constructivist movement advanced by, in particular, Piaget [9], Bruner [2] and Kelly [6]. In keeping with this constructive view of teaching, attribution theory has come to serve as a potential area that could be fruitfully explored in

\footnotetext{
${ }^{a}$ Corresponding author: cyilmaz@comu.edu.tr
} 
order to reach a better understanding of individuals in the process of language teaching and learning.

The theoretical framework adopted for present study is that of Weiner's attribution theory $[11,12]$. A central aspect of Weiner's theory was that it was how people perceived events rather than the events in themselves that influenced behavior [14]. It is apparent that attribution is the process of attributing a cause to an event in which people strive to determine the reasons and explanations for success and failure in order to make sense of observed events, and as a result, predict the course of similar future behaviors. It has been suggested that students interpret their achievement outcomes, particularly, how they explain success and failure, by attributing causes to them [5]. When a student attributes his failure to lack of effort or ability or to some action, as Weiner [12] points out, it is likely to affect that person's subsequent actions.

Essentially, Weiner's construction of his own influential version of attribution theory is mainly concerned with degrees of achievement, and perceptions of how far this achievement has been attained. To make this clearer, if you simply were to ask people to what they attributed their success or failure on a particular language learning task, they might give a variety of replies [14]. To illustrate how this might work, some possible attributions often cited by learners of English would be: 'I am good at learning languages' or 'I worked hard'.

Along with Weiner's attribution theory, it is widely acknowledged that people tend to refer to four main sets of attributions to articulate their perceived successes and failures in the realm of education. This is true for language education. These attributions include: (a) ability, (b) effort, (c) luck, (d) the perceived difficulty of the task with which they are faced. In addition, attributions are categorized as either internal (for instance ability and effort) or external (for instance task difficulty and luck).

The growing body of research regarding attribution revealed significant tendencies on the part of students as the main reason for success and failure in foreign language. A study conducted by Weiner [12] demonstrates how a group of primary and secondary students had varying tendencies to attribute success to both internal and external factors in learning a foreign language. It was found that students attributed success to internal effort whereas they were at the same time reported to cite external factors such as distraction, by others, difficulty of work and poor teaching as the main reasons for failure [8, 12]. This is particularly felt when some students do not see the point of working hard and therefore tend to make less effort than is desirable. To go about this detrimental aspect of attribution Peacock [8] proposes that attributions can be modified once they are identified. And beyond this, he adds that modifications make room for the action to be taken by the learner in this process.

In line with the above considerations embedded in Weiner's attribution theory, in recent years there have been a significant number of studies investigating the attribution patterns concerning success and failure within the context of English Language Teaching [7, 8, 15 and 16]. In a large-scale study, Burden, [15] attempted to determine secondary students' attributions for their success and failure in learning foreign languages. The study also looked at the ways in which these vary according to the variables such as age, gender and perceived success. Over one thousand attributional statements gave rise to 21 attributional categories for doing well and 16 categories for not doing well at language learning, six of which were commonly cited as reasons for both success and failure. These attributions included effort, strategy, ability, task, teacher, interest, and peers. A similar study [7] was administered to 81 students and asked them why they succeeded in a foreign language: they generated a different set of attributions. Consequently motivation, a comfortable pace, a good teacher, ability, time and effort were the most common explanations of success. 
The present study sets out to show that Turkish student teachers' individual beliefs and experiences are central to an in-debt analysis of student attributions in English which will in turn affect both the way in which they learn and the outcomes of the language learning process. What emerges from the study is that teacher trainees are observed to act as truly autonomous learners as they respond to questions pertaining their attributions in English. That is to say, the teacher trainees' engagement with the issues of attributions in the course of the study in turn proves useful as they become aware of their own attributions in English. As Peacock [8] stressed, it is critical to promote teacher awareness of the existence and causes of attribution and inform them that it is possible to promote helpful attribution.

\section{Aim of the Study}

The present study was primarily concerned with exploring EFL pre-service students' perceived attributions involved in the teaching-learning process in a Turkish context. The study further aimed to investigate the relationship between pre-service teachers' attributions, their gender, and proficiency. The study was designed to fit an EFL context, drawing upon the model proposed by William, Burden, Poulet, and Maun (2004). To do this, the following research questions were addressed for this study:

1. To what do pre-service teachers attribute their success and failure in English?

2. Is there a significant relationship between pre-service teachers' attributions and their gender?

3. Is there a significant relationship between pre-service teachers' attributions and their proficiency?

\section{Methods}

\subsection{Participants}

There were 122 pre-service teachers taking part in this study. They were all senior students majoring in English language teaching (ELT) at Çanakkale Onsekiz Mart University. Of these students, $75(61.6 \%)$ were female and $47(38.4 \%)$ were male. Typical of the population of ELT in Turkish context, students were ranging in age from 18 to 24, with 810 years of language learning experience. To obtain reliable data, the participants were briefed for the purpose of the attribution questionnaire and assured of confidentiality in that they were not required to write their names on the questionnaires. In an attempt to assess the actual proficiency in English, the subjects were asked to report on their cumulative average of the English courses that they have taken up to the point of completing the questionnaire. The averages were classified as 2.5-4.00=good, and less than $2.5=$ poor, assuming that the passing average is nearly 2.5 over 4.0 .

\subsection{Instrument and Procedures}

The present study adopted a mixed methods research in nature. Dörnyei [3] defines a mixed methods study as one that involves both qualitative and quantitative data in a single study. As part of the qualitative component to the research, the researcher initially interviewed 20 students, mixed by gender and proficiency level, and asked them to what they attribute EFL success and failure in English. For this purpose, a simple questionnaire was constructed consisting of two open-ended statements, which was adapted from Williams and Burden [14] as the following: 
1. When I do well in English, the main reasons are.

2. When I don't do well in English, the main reasons are.

Students' responses were collected and analyzed using a grounded approach [10] that is often taken as a synonym for qualitative approach. This in effect enabled the researcher to interpret students' intended views and to allow the categories to emerge from the data. It was found that students gave 18 reasons for success and 12 for failure. With totally these 30 attributions the researcher designed a questionnaire using a five-point scale. As for data analysis in the questionnaire that makes up the quantitative component, the mean scores and standard deviations for each item in the questionnaire were calculated using SPSS V. 16.0. The criteria used for evaluating the degree of attribution frequency are : low frequency use (1.0-2.49), moderate frequency use (2.5-3.49), and high frequency use (3.55.0). Further, Independent Sample t-test was conducted to identify the connections between attribution and gender, and proficiency. In this study, the total level of reliability of the student questionnaire, estimated via Cronbach' alpha, was calculated at a high 0.84 .

\section{Results}

\subsection{Pre-service teachers' attributions for success and failure in English}

18 attributions for success and 12 for failure in English emerged from the data (Table 1 and Table 2). Table 1 reveals descriptive statistics of pre-service teachers' attributions for success in ranked order.

Table 1. Pre-service teachers' attributions for success in English

\begin{tabular}{lll}
\hline Attributions for success & Mean & SD \\
\hline I have a talent in learning English & 4.14 & .865 \\
I took a keen interest in English & 4.29 & .776 \\
I regulated my own learning & 4.04 & .857 \\
Good rewards and grades promoted success & 4.04 & 1.06 \\
I took field notes to remind me what to revise & 4.01 & .858 \\
I felt the need to study & 3.98 & .799 \\
A wide range of different tasks were introduced & 3.96 & .829 \\
I received overwhelming support from family & 3.87 & 1.27 \\
I was in the mood to study English & 3.85 & .865 \\
Teachers allowed enough time to practice in class and to finish in & 3.75 & 1.03 \\
exams & & \\
The classroom environment had a positive effect & 3.69 & 1.15 \\
I worked hard for success & 3.67 & 1.11 \\
Teaching materials were used effectively & 3.64 & .942 \\
The circumstances for training were promising & 3.59 & .858 \\
I worked with a partner & 3.43 & .968 \\
The task undertaken was easy & 3.08 & .835 \\
I always asked my teacher for help & 3.08 & 1.13 \\
I was simply lucky & 2.85 & .955 \\
\hline Total mean & 3.72 & .953 \\
\hline
\end{tabular}


As Table 1 shows, pre-service teachers appear to possess a variety of attributions towards learning EFL. Notably, pre-service teachers' attributions had high mean values with the total mean value of 3.72, supporting the view that they held strong perceptions of the reasons behind their success in English. Of all 18 items, it was found that the item 1 had the highest mean value (4.14) which means that pre-service students strongly attributed student success to ability. As such, these abilities involved having a talent in English with the highest mean score, regulating own learning $(M=4.04)$ and taking field notes $(M=4.01)$. The next common theme reported was related to the attribution effort that pre-service teachers devoted to studying English. This category included working hard for success $(M=3.67)$, working with a partner, and feeling the need to study $(M=3.98)$. The next attribution to emerge was termed task difficulty. This included items such as introducing a wide range of different tasks $(M=3.96)$, using teaching materials effectively $(M=3.64)$, and undertaking easy tasks $(\mathrm{M}=3.08)$. Further, as the results demonstrated, the respondents perceived luck as having the least impact on success in English $(\mathrm{M}=2.85)$. For educational purposes, as Schuman (2011) asserted in a similar study, this viewpoint is encouraging because teacher trainees tend to view success as being in the control of the learner rather than as a result of external factors. In addition to these emerging success attributions embedded in four common themes, the pre-service teachers attributed success to the other reasons including interest in English $(M=4.29)$, good grades in exams $(M=4.04)$ as well as support from family and teachers, positive classroom environment and effectively used teaching materials. Generally speaking, most of these attributions are internal to subject, unstable (i.e. open to change), and controllable (i.e. under subjects' control).

The study then sought to determine pre-service teachers' perceived attributions for not doing well, relying on the identical categories. As shown in Table 2, twelve attributions for not doing well emerged from the data, corresponding to nine of the categories for doing well. Table 2 reveals descriptive statistics of pre-service teachers' attributions for failure in ranked order.

Table 2. Pre-service teachers' attributions for failure in English

\begin{tabular}{lll}
\hline \multicolumn{1}{c}{ Attributions for failure } & Mean & SD \\
\hline I was not simply lucky & 3.40 & 1.10 \\
The tasks / exams were difficult & 3.27 & 1.08 \\
I didn't always ask my teacher for help & 3.11 & 1.33 \\
I didn't work hard for success & 2.80 & 1.27 \\
A wide range of different tasks were not introduced & 2.75 & 1.08 \\
I didn't take field notes & 2.64 & 1.05 \\
I didn't work with a partner & 2.61 & 1.23 \\
I lacked confidence in English & 2.56 & 1.12 \\
Teaching materials were not used effectively & 2.54 & 1.09 \\
I was unable to regulate my own learning & 2.46 & 1.16 \\
Teachers didn't allow enough time to practice in class and to finish & 2.46 & 1.15 \\
in exams & & \\
I didn't take a keen interest in English & 2.00 & .991 \\
\hline Total mean & 2.71 & 1.05 \\
\hline
\end{tabular}

At this point, it is critical to note that pre-service teachers' failure attributions had relatively lower mean values with the total mean value of 2.71 compared to those of 
success attributions. That's to say, they appear to have moderate perceptions of failure attributions in acquiring English skills. The results, though, are of considerable importance in making it possible to gain valuable insights into the nature of failure attributions in English. As the data presented in Table 2 makes it clear that the majority of the student teachers strongly attributed failure to external factors such as luck, task or exam difficulty, teacher help, teaching materials and variety. At this point, it is important to note that these are uncontrollable attributions while the remaining attributions including hard work, interest and self-confidence are internal to students, and controllable.

\subsection{The relationship between pre-service teachers' attributions and gender}

In order to investigate the impact of gender on pre-teachers' perceived attributions, Independent Sample T-test was conducted. As illustrated in Table 3, meaningful differences at $(\mathrm{p}=.05)$ were found between student teachers' attributions and gender. There were two statistically significant differences. Females were significantly more likely to attribute success to both working hard for becoming competent in English $(p=.001)$ and circumstances $(\mathrm{p}=.001)$ which might in effect facilitate the learning process if geared towards meeting their language needs.

Table 3. Results of t-test for the differences in student attributions according to gender variable

\begin{tabular}{lllllll}
\hline Attributions & Gender & $\mathrm{N}$ & Mean & SD & $\mathrm{t}$ & Sig. \\
\hline Working hard & Male & 47 & 3.05 & 1.16 & -3.34 & .001 \\
& Female & 75 & 4.16 & 1.18 & & \\
Circumstances & Male & 47 & 3.38 & 1.09 & -4.21 & .001 \\
& Female & 75 & 4.42 & .76 & & \\
\hline
\end{tabular}

\subsection{The relationship between pre-service teachers' attributions and proficiency}

In an attempt to address the third research question, the Independent Sample T-test was again adopted as a statistical means to analyze the correlation between pre-service teachers' attributions and proficiency.

Table 4. Results of t-test for the differences in student attributions according to proficiency

\begin{tabular}{lllllll}
\hline Attributions & Proficiency & $\mathrm{N}$ & Mean & SD & t & Sig. \\
\hline Working hard & Good & 63 & 4.44 & .63 & 2.71 & .009 \\
\multirow{3}{*}{ Talent } & Poor & 59 & 3.87 & .96 & & \\
& Good & 63 & 4.17 & .88 & 3.58 & .001 \\
& Poor & 59 & 3.24 & 1.11 & & \\
\hline
\end{tabular}

As displayed in Table 4, there were two statistically significant attributions at $(p=.05)$ that were identified by pre-service teachers. These included making great efforts by working hard $(\mathrm{p}=.009)$ in order to accomplish demanding English courses, and possessing distinctive natural talents $(\mathrm{p}=.001)$ for acquiring languages. Accordingly, more proficient pre-service teachers attributed success to these two emerging factors. The results make it clear that more proficient students attributed success primarily to their own efforts and 
abilities alongside the language education process Clearly, this was not the case with less proficient student teachers, who attributed both success and failure to other factors such as lack of enjoyment or easy tests.

\section{References}

1. Biddle, S.. Attribution research and sport psychology. In R. N. Singer, M. Murphey and L. K. Tennant (Eds.) Handbook of Research on Sport Psychology. (pp. 437-64). New York: Macmillian, (1993).

2. Bruner, J. S.. The Process of Education. Cambridge, Mass.: Harvard University Press, (1960).

3. Dörnyei, Z. Research Methods in Applied Linguistics. Oxford: Oxford University Press, (2007).

4. Driscoll, M. P. Psychology of Learning for Instruction. Toronto, ON: Pearson, (2005).

5. Eccles, J. S. Motivational beliefs, values, and goals. Annual Review of Psychology, 53, 109-132, (2002).

6. Kelly, G. The Psychology of Personal Constructs. New York: Norton, (1955).

7. McQuillan, J. Attribution theory and second language acquisition: an empirical analysis. Paper presented at AAAL Conference. Vancouver, (2000).

8. Peacock, M. Attribution and learning English as a foreign language. ELT Journal, 64(2), 184-192, (2009).

9. Piaget, J. To Understand is to Invent. New York: Viking Press, (1974).

10. Strauss, A. L. and Corbin, J. Basics of Qualitative Research: Techniques and Procedures for Developing Grounded Theory, 2nd Edition. Thousand Oaks, Calif.: Sage, (1990).

11. Weiner, B. A theory of motivation for some classroom experiences. Journal of Educational Psychology, 71, 3-25, (1979).

12. Weiner, B. Human Motivation. New York: Holt, Rinehart and Winston, (1980).

13. Weiner, B. An Attributional Theory of Motivation and Emotion. New York: SpringerVerlag, (1986).

14. Williams, M. and Burden, R. L. Psychology for LanguageTeachers. Cambridge: Cambridge University Press, (1997).

15. Williams, M., Burden, R. L., Poulet, G. and Maun, I. Learners' perceptions of their successes and failures in foreign language learning. Language Learning Journal, 30, 19-29, (2004).

16. Yilmaz, C. An investigation into Turkish EFL students' attributions in reading comprehension. Journal of Language Teaching and Research, 3, 823-29, (2012). 